IZA DP No. 3469

\title{
Endogenous Reversals of Fortune
}

\author{
Mark Gradstein
}

April 2008 


\title{
Endogenous Reversals of Fortune
}

\author{
Mark Gradstein \\ Ben Gurion University, \\ CEPR, CESifo and IZA
}

\section{Discussion Paper No. 3469 \\ April 2008}

\author{
IZA \\ P.O. Box 7240 \\ 53072 Bonn \\ Germany \\ Phone: +49-228-3894-0 \\ Fax: +49-228-3894-180 \\ E-mail: iza@iza.org
}

\begin{abstract}
Any opinions expressed here are those of the author(s) and not those of IZA. Research published in this series may include views on policy, but the institute itself takes no institutional policy positions.

The Institute for the Study of Labor (IZA) in Bonn is a local and virtual international research center and a place of communication between science, politics and business. IZA is an independent nonprofit organization supported by Deutsche Post World Net. The center is associated with the University of Bonn and offers a stimulating research environment through its international network, workshops and conferences, data service, project support, research visits and doctoral program. IZA engages in (i) original and internationally competitive research in all fields of labor economics, (ii) development of policy concepts, and (iii) dissemination of research results and concepts to the interested public.
\end{abstract}

IZA Discussion Papers often represent preliminary work and are circulated to encourage discussion. Citation of such a paper should account for its provisional character. A revised version may be available directly from the author. 
IZA Discussion Paper No. 3469

April 2008

\section{ABSTRACT}

\section{Endogenous Reversals of Fortune}

The phenomenon of systemic changes in the fortunes of social groups is hard to reconcile with traditional macroeconomic models of intergenerational mobility. This paper, therefore, proposes a theory of endogenous reversal of fortune, whereby instilling strict work norms is an instrument to address moral hazard in poor families more so than in rich families, which is consistent with empirical regularities pertaining to work attitudes. The mechanism implies that hard-working children of the poor may eventually overtake leisure-prone children of the rich. This evolution, in particular, of work norms, is endogenously determined and is, therefore a better explanation of the rise and the fall of population groups than existing theories that rely on exogenous ability variations.

JEL Classification: D31, J62

Keywords: $\quad$ work norms, intergenerational income mobility

Corresponding author:

Mark Gradstein

Department of Economics

Ben-Gurion University of the Negev

P.O. Box 653

Beer-Sheva 84105

Israel

E-mail: grade@bgu.ac.il 


\section{Introduction}

Intergenerational mobility issues have long been of interest for economists both theoretically and empirically (e.g., Becker, 1981, Becker and Tomes, 1988, Loury, 1981). Typically, innate ability differences play an essential role in theories explaining intergenerational mobility, see e.g., Maoz and Moav, 1999, Mookherjee and Napel, 2006, for recent models. This, however, is difficult to reconcile with historical rise and fall of entire groups of individuals. ${ }^{1}$ The fall and rise of social elites is one such example. European nobility, dominant in earlier centuries, gave away its power and the landowner class lost much of its economic significance in the course of the nineteenth century; in contrast, the bourgeoisie and the intelligentsia, rose to become dominating social classes (see Bertocchi, 2006, for a detailed discussion). Another set of important examples constitute religious or ethnic groups as well as immigrants. In particular, the latter - typically without much physical capital or educational background - often are more upward socially mobile than the locals in the host societies. $^{2}$

Social thinkers, when put to the task of addressing these phenomena, have often singled out norms, such as hard work or the drive for educational attainment, as an explaining factor. The famous Weberian work ethic argument is just one, the most prominent of such theories. This line of reasoning, however, leaves unexplained the emergence of such norms, in particular, among relatively disadvantaged individuals.

\footnotetext{
${ }^{1}$ Among the many factors that work against mobility are differential access to credit between the poor and the rich, especially coupled with opportunities for private schooling, and differential access to influential social networks.
} 
Recent research in economics has attempted to endogenize culturally transmitted norms that may have economic implications. For example, Bisin and Verdier, 2001, offer a general approach to the intergenerational transmission of preferences; Gradstein and Justman, 2002, discuss its implications in the context of comparison of schooling systems; Botticini and Eckstein, 2005, 2006, deal with some of its labor market implications; and Becker and Woesmann, 2007, empirically argue that the leading factor behind the Weberian work ethic attributed to Protestantism was not its religious slant, but rather its emphasis on human capital acquisition.

This paper's goal is to provide a framework for the analysis of the dynastic "reversal of fortune" across generations, especially focusing on an endogenous mechanism for its emergence. In particular, I study incentive issues within a family and parental instilling of work attitudes as the means to boost up children incentives. ${ }^{3}$ The possibility of such attitudes being inversely related to family wealth is exhibited - implying spoiled children of rich parents and hard working children of poor parents. ${ }^{4}$ Survey based evidence, discussed below, strongly indicates existence of such inverse relationship. This, in turn, may imply impoverishment of rich dynasties relative to the poor ones, which is in particular consistent with the success of second generation immigrants well documented in the literature, see Carliner, 1980, Chiswick, 1977, Card, 2005.

\footnotetext{
${ }^{2}$ Specific examples include ethnic Indians in Africa and ethnic Chinese in Malaysia, see Sowell, 1996, for a more detailed account.

${ }^{3}$ The evolving literature on the formation on social norms has proceeded mainly along two lines. One line emphasizes cultural evolution; Galor and Moav, 2002, is a seminal contribution that applies this approach to study long run economic growth. This paper is along the second line that focuses on deliberate socialization as in the above cited papers.
} 
The paper is related to the literature on intergenerational income mobility, as in Becker and Tomes, 1986, Loury, 1981, Maoz and Moav, 1999, Mookherjee and Napel, 2006. The emphasis here, however, is on the endogenization of the rise and fall of dynasties, as opposed to attributing it to random variations in abilities. This, of course, is not to suggest that the latter is not relevant, and the two approaches should be rather viewed as complementary. Bertocchi, 2006, and Galor and Moav, 2006, are the only papers we are aware of that pursue the endogenization route, both to address the demise of the traditional class structure. The former paper focuses on the changes in the inheritance laws, whereas the latter paper attributes it to the (endogenous) emergence of public education in the context of economic growth; here, in contrast, the emphasis is on the evolution of work attitudes. While the paper provides a complementary to the above work explanation to the demise of aristocracy, it is also consistent with economic successes of second generation immigrants, as discussed more in detail below.

Another relevant literature is on the implications of the transmission of social norms as in Botticini and Eckstein, 2005, 2006, and Becker and Woesmann, 2007. Of most direct relevance here is Doepke and Zilibotti, 2007 (also Doepke and Zilibotti, 2005), who also study the implications of time preference as well as work norms on social mobility focusing on the occupational choices. ${ }^{5}$ While closely related to this paper's interest, Doepke and Zilibotti's, 2007, mechanism is very much different from the one exhibited below; in particular, they consider the slope of the earnings' profile across generations as the determining factor, ignoring family incentives, considered crucial here. Specifically, in Doepke and Zilibotti,

\footnotetext{
${ }^{4}$ This captures the so called "Carnegie effect", according to which inherited wealth "deadens the talents and energies of the son, and tempts him to lead a less useful and less worthy life than he otherwise would."
} 
2007, the poor prefer their children to be patient and hard working in anticipation of their choosing an occupation with a steep wage increase, so that aspects of preferences and occupation choices are mutually reinforcing. Here, in contrast, the poor instill in their children working habits as a commitment device, to minimize children dependence on parental transfers. ${ }^{6}$ The two approaches should be viewed as complementary.

A third related strand is the literature on family interaction, starting with Becker's 1974, seminal work. Gatti, 2005 (see also the references therein), for example, discusses the efficiency implications of parental inability to commit to transfers. Lindbeck and Nyberg, 2006, analyze instilling work norms as parental instrument to reduce children moral hazard; but they ignore the effect of parental wealth in this regard, as well as its dynamic implications. In the model below, aspects of family interactions featured in the literature are imbedded in a dynamic dynastical context to address the issues at hand.

The rest of the paper proceeds as follows. Section 2 discusses some empirical motivation. The model is then introduced in Section 3, followed by its analysis, in Section 4 . Section 5 contains extensions of the basic analysis, and Section 6 concludes.

\footnotetext{
${ }^{5}$ On the latter aspect, see also Galor and Tsiddon, 1997, whose model's implications are remarkably consistent with the swings in the US income distribution.
} 


\section{Motivation}

Several pieces of historical and empirical evidence motivate this research. Recent work Bertocchi, 2006, and Doepke and Zilibotti, 2007, argues that landowner classes in European countries did not reap at all the opportunities offered by the Industrial Revolution, which is viewed as surprising given their economic wealth and political clout. This is interpreted as the unwillingness on their part to forgo immediate life comfort in order to pursue for the young children demanding occupational careers; in contrast, middle classes were prepared to undertake long term human capital investments. Further, it is argued that the consumption of leisure by the landed aristocracy was measurable higher, whereas industrious and financial investment activity was lower, than in the case of the middle class.

Evidence on the economic assimilation of immigrants is in some sense even more relevant. Semi-anecdotal stories about immigrants' hard working attitudes and economic successes are abundant, see Sowell, 1996, for these in the context of several ethnic immigrant groups. A more carefully compiled piece of evidence comes from the analysis of second generation immigrants. ${ }^{7}$ This literature has followed the lead of Chiswick, 1977, 1978, who finds income convergence across the first two immigration cohorts in the US. Borjas, 1993, in the US context and Hammarstedt and Palme, 2006, in the context of Sweden, using detailed datasets find strong evidence of income convergence from the first to the second generation of immigrants; both works also discern a large variation across the immigrants' countries of

\footnotetext{
${ }^{6}$ There some additional, more minor differences, such as the modeling of the motivation behind instilling of work attitudes: in Doepke and Zilibotti, 2007, this is driven solely by altruism, whereas in the model below, the parents also value their children sharing similar work attitudes.

${ }^{7}$ Defined as local-born individuals to foreign-born parents.
} 
origin, which in itself is a significant contributing factor to the immigrants' earnings. More importantly for this paper's argument, Card, 2005, reviewing several recent studies in the US context, comes to the conclusion that second generation immigrants not only close the gap, but - controlling for the country of origin - have higher education levels than the natives in their cohort, indicating a reversal of fortunes. ${ }^{8}$

Micro evidence on how family income shapes schooling and work attitudes is scarce. Thus, Jacob and Lefgren, 2007, find that low-income parents tend to place a larger weight of their children scholastic achievements relative to high-income parents, who instead value children general satisfaction with the attended school. Another piece of tentative evidence is survey based. The World Values Surveys, a world wide survey carried out by the InterUniversity Consortium for Political and Social Research (ICPSR) that comprises individual cross national questions on a wide variety of topics, provide an opportunity to get a sense to which the inverse relationship between material background and work attitudes holds in a large sample of countries and respondents. Data in these surveys are generated from face to face interviews to a sampling universe of adult citizens 15 years old and older, and we focus on the fourth wave in the course of which tens of thousands of individuals were surveyed during 1997-2004.

\section{Insert Table 1 Here}

Table 1 presents illustrative regression results. ${ }^{9}$ Its first two columns focus on the question that

\footnotetext{
${ }^{8}$ Specifically, vast majority of country-of-origin groups have done better than the natives. It should, however, be noted that the number of truly longitudinal studies on these issues, especially outside of the US, is limited.

${ }^{9}$ The dependent variables are categorical, and thus the coefficients are estimated using ordered probits.
} 
seeks the extent of agreement with the statement "Work is what makes life worth living, not leisure". ${ }^{10}$ The specification in its first column includes individual income as well as gender and family status characteristics. Income is seen to be negatively related to the value of work and is strongly significant. One potential concern is that this relationship is driven by education: more educated individuals may work more and hence value more leisure on the margin. To address this issue, the second column adds the education variable. Indeed, this variable is significant and is negatively related to work attitude. Further, the statistical significance of the income variable is somewhat reduced; however, it still remains highly significant. Qualitatively equivalent findings are obtained when the dependent variable refers to a different question in the surveys, "Work should always come first, even if it means less spare time"; see columns 3 and 4 for its analysis. The results are very much similar to the ones in columns 1 and 2. Overall, therefore, survey data is indicative of a negative relationship between individual income and work attitudes. ${ }^{11}$

\section{The model}

Consider an OLG economy, with an infinite number of households, indexed $i$, consisting each of a parent and a child, operating in discrete time $t$. A household is initially characterized by income $y_{i 0}>0$ and by a work norm, $0<\delta_{i 0}<1$, whose both distributions are given and are independent; incomes and work norms in future periods will be endogenously determined in the model. The family's child is endowed with one unit of time.

\footnotetext{
${ }^{10}$ The definitions of the variables used are described in the appendix.
} 
In each generation income is disposed by the parent, and is allocated between consumption, $c_{i t}$, and bequest transfers to the child, $b_{i t+l}$ while respecting the budget constraint

$$
y_{i t}=c_{i t}+b_{i t+1}
$$

The parents also instill in children work attitudes or work norms, represented by the parameter $\delta_{i t+1}$, normalized to lie in the unit interval. This assumption is consistent with the theories of deliberate socialization, as in, for example, Bisin and Verdier, 2001, Gradstein and Justman, 2002. Most of the literature in social psychology views the parents as the primary source of social influence and also attests to the importance of parental socialization of work attitudes, see Eccles et al., 2000. As an extension below I briefly discuss some more general forms of cultural transmission.

The assumption of there being just one offspring greatly simplifies the analytics. With multiple offspring, intergenerational strategic interactions could become more involved, especially when the parents are able to manipulate the inheritance rule. Recent work addresses empirical inheritance patterns, such as the fact that most parents choose equal division of wealth among the offspring. In this context, Bernheim and Severinov, 2003, show how by equally dividing bequests, the parents can signal patterns of intergenerational altruism that minimize their children moral hazard. We abstract from these issues here.

The young individual allocates time between effort $n_{i t+1}$ and leisure, $1-n_{i t+1}$. The effort could be interpreted as work, and it generates income of $a_{t+1} n_{i t+1}$ where $a_{t+1}$ is the exogenously

\footnotetext{
${ }^{11}$ Adding additional controls, such as the respondent's age or political attitudes, qualitatively reinforces this conclusion.
} 
given labor productivity parameter. The next-period income is then jointly determined by parental transfers and young worker's effort,

$$
y_{i t+1}=a_{t+1} n_{i t+1}+b_{i t+1}
$$

The young individual's utility is defined over income and leisure, as follows:

$$
V\left(y_{i t+1}, 1-n_{i t+1}\right)=\log \left(y_{i t+1}\right)+\left(1-\delta_{i t+1}\right) \log \left(2-n_{i t+1}\right)
$$

where $0 \leq \delta_{i t+1} \leq 1$ is interpreted as the work attitude or the work norm and is determined by the parents. $^{12}$

Parents are altruistic toward the children, and they derive utility from consumption; incur an emotional cost from having children with different work attitudes than themselves; and their utility subsumes their child's one. While parents may have multiple motivations for instilling work attitudes in their children, sharing a common values system is most likely one of these, as is evidenced in the social psychology literature (see Eccles et al., 2000, and references therein). This motivation is also related to the vertical transmission of cultural values in the influential work of Cavalli-Sforza and Feldman, 1981, and Boyd and Richerson, 1985. We, in particular, assume the following specification:

$$
U\left(\delta_{i t+1}, c_{i t}, V\right)=-C\left(\delta_{i t+1}-\delta_{i t}\right)+\log \left(c_{i t}\right)+V\left(y_{i t+1}, 1-n_{i t+1}\right)=
$$




$$
-C\left(\delta_{i t+1}-\delta_{i t}\right)+\log \left(c_{i t}\right)+\log \left(y_{i t+1}\right)+\left(1-\delta_{i t+1}\right) \log \left(2-n_{i t+1}\right)
$$

where $C^{\prime}, C^{\prime \prime}>0$.

A period describes a lifespan. In each period, the sequence of events is as follows. First, the parents instill work attitudes by setting $\delta_{i t+l}$. Then the young individual allocates unit of time between effort and leisure. Finally, the parents determine the bequest transfers that jointly with the young individuals' efforts determine next period income. In equilibrium, these choices have to be mutually consistent. ${ }^{13}$

\section{Analysis}

We proceed backwards. At the last stage, the parents leave bequests that maximize the utility (4), while taking account of (2), respecting the budget constraint (1) and treating prior choices as given. Analysis of the first order conditions,

$$
-1 /\left(y_{i t}-b_{i t+1}\right)+1 /\left(a n_{i t+1}+b_{i t+1}\right) \leq 0
$$

and assuming internal solutions for simplicity, reveals that the optimal budget allocation is given as follows:

\footnotetext{
${ }^{12}$ Many of the results go through for general sub-utility functions, as was shown in the previous version of the paper; the logarithmic specification generates particularly tractable analysis. Note that the derivative of the sub-utility from leisure is positive when the individual only consumes leisure, which constitutes a further analytical simplification.

${ }^{13}$ The basic intra-period decision making structure is similar to Lindbeck and Nyberg, 2006, with two main differences. First, Lindbeck and Nyberg, 2006, essentially assume group influences on the social norm; whereas
} 


$$
b_{i t+1}=\left(y_{i t}-a_{t+1} n_{i t+1}\right) / 2, c_{i t}=y_{i t+1}=\left(y_{i t}+a_{t+1} n_{i t+1}\right) / 2
$$

Anticipating these decisions, the young now allocate the time unit between effort and leisure so as to maximize (4). In other words, a young individual makes her choices acting as a Stackelberg leader with respect to her parent.

Assuming internal solutions for simplicity, the first order conditions optimally balance the contribution of work to the young person's income and the consumption of leisure, and are formally given as follows:

$$
a_{t+1} /\left(y_{i t}+a_{t+1} n_{i t+1}\right)-\left(1-\delta_{i t+1}\right) /\left(2-n_{i t+1}\right)=0
$$

and the second order conditions hold as revealed by differentiating the left hand side in (6); the equilibrium amount of work is then given by:

$$
n_{i t+1}=\left[2-\left(1-\delta_{i t+1}\right) y_{i t} / a_{t+1}\right] /\left(2-\delta_{i t+1}\right)
$$

It will be useful to observe that a corner solution, $n_{i t+1}=1$, is obtained whenever $\delta_{i t+1}>(1-$ $\left.\left.\delta_{i t+1}\right) y_{i t} a_{t+1}\right]$ and, in particular, when $\delta_{i t+1}$ is close to one, or when the family income level is small enough. Likewise, $n_{i t+1}=0$, is obtained whenever $\left(1-\delta_{i t+1}\right) y_{i t} / a_{t+1}>2$ and, in particular, when $\delta_{i t+l}$ is small enough, or when family income is large enough.

Also note that

here, instead, work norms are transmitted within a family, through individual decisions. More importantly, their utility assumptions essentially assume away potential income effects, which are essential here. 
$1-n_{i t+1}=\left[-\delta_{i t+1}+\left(1-\delta_{i t+1}\right) y_{i t} / a_{t+1}\right] /\left(2-\delta_{i t+1}\right) ; 2-n_{i t+1}=\left(1-\delta_{i t+1}\right)\left(2+y_{i t} / a_{t+1}\right) /\left(2-\delta_{i t+1}\right)$

As revealed by differentiating (7), young individuals' work time increases in the work norm parameter $\delta_{i t+1}$, more so the higher parental income:

$$
d n_{i t+1} / d \delta_{i t+1}=\left(2+y_{i t} / a_{t+1}\right) /\left(2-\delta_{i t+1}\right)^{2}>0, \text { and } d^{2} n_{i t+1} / d y_{i t} d \delta_{i t+1}>0
$$

and decreases in family income:

$$
d n_{i t+1} / d y_{i t}=-\left[\left(1-\delta_{i t+1}\right) / a_{t+1}\right] /\left(2-\delta_{i t+1}\right)
$$

Both results are intuitive, as stricter work norms imply a lower marginal utility from leisure; and a higher level of family income leads to higher future bequests. It then also follows that future income, $y_{i t+l}$, increases in the work attitude, as revealed by differentiation of $y_{i t+l}$ in (5).

Before proceeding to analyze parental instilling of work norms, it is useful to compare the Stackelberg equilibrium solutions derived above to the corresponding values that would have been chosen by the parents had they control over children time allocation decisions. In the latter case, parental optimal choices satisfy the first-order conditions:

$$
\begin{aligned}
& -1 /\left(y_{i t}-b_{i t+1}\right)+1 /\left(b_{i t+1}+a_{t+1} n_{i t+1}\right)=0, \\
& a_{t+1} /\left(b_{i t+1}+a_{t+1} n_{i t+1}\right)-\left(1-\delta_{i t+1}\right) /\left(2-n_{i t+1}\right)=0
\end{aligned}
$$

Solving this system we obtain: 
$n_{i t+1}^{\mathrm{C}}=\left[2-\left(1-\delta_{i t+1}\right) y_{i t} / 2 a_{t+1}\right] /\left[1+\left(1-\delta_{i t+1}\right) / 2\right], b_{i t+1}^{\mathrm{C}}=\left[\left(2-\delta_{i t+1}\right) y_{i t}-2 a_{t+1}\right] /\left[1+\left(1-\delta_{i t+1}\right) / 2\right]$

and direct comparisons with the equilibrium values above establish the following intuitive results:

Proposition 1. For given work norms, the chosen equilibrium effort by the young is smaller and the amount of parental transfer is larger than the ones the parents would have chosen having full control over both decisions. ${ }^{14}$

The key here is the moral hazard of the child, who - anticipating parental altruistic transfer puts in too little effort from parental perspective. This is similar to the results in Gatti, 2005 (see also the work cited there), which in turn builds upon Becker, 1974, 1981. It is essential for these results that the parents are unable to make their bequests fully contingent on children efforts; and that the scope for intergenerational bargaining on these issues is limited.

These results suggest some of the motivations parents have when molding children attitudes. A stricter work norm would increase the child's work effort, potentially bringing it closer to parental bliss point. A counter-balancing factor is the smaller utility from child's leisure that is also valued by the parents. And a final consideration is parental desire to have children with work norms similar to themselves.

\footnotetext{
${ }^{14}$ Further, in the previous version of the paper it was also shown that the period equilibrium choices are socially sub-optimal for given work norms.
} 
We now turn to formally study the determination of work norms by the parents. In contemplating so doing, the parents maximize their utility while anticipating the decisions above. Employing the envelope theorem, the resulting first order conditions are as follows:

$$
\begin{aligned}
& -\mathrm{C}^{\prime}\left(\delta_{i t+1}-\delta_{i t}\right)+\left(a_{t+1} /\left(y_{i t}+a_{t+1} n_{i t+1}\right)\right) d n_{i t+1} / d \delta_{i t+1}-\log \left(2-n_{i t+1}\right)= \\
& -\mathrm{C}^{\prime}\left(\delta_{i t+1}-\delta_{i t}\right)+\left[\left(1-\delta_{i t+1}\right) /\left(2-n_{i t+1}\right)\right]\left[\left(y_{i t} / a_{t+1}+2\right) /\left(2-\delta_{i t+1}\right)^{2}\right]-\log \left(2-n_{i t+1}\right)= \\
& -\mathrm{C}^{\prime}\left(\delta_{i t+1}-\delta_{i t}\right)+1 /\left(2-\delta_{i t+1}\right)-\log \left(2-n_{i t+1}\right)=0
\end{aligned}
$$

The three terms in (10) represent, respectively, parental psychic cost of having a child with different work norms than herself; the contribution of stronger work norms for the child's income; and the reduction in child's utility from leisure as a consequence of work oriented attitudes. We assume that the left-hand side in (10) is positive at $\delta_{i t+1}=0$ and is negative at $\delta_{i t+1}=1$, implying that (10) characterizes a utility maximizing work norm whenever the second order conditions hold, that is, when

$$
\text { S.o.c. }=-\mathrm{C}^{\prime \prime}\left(\delta_{i t+1}-\delta_{i t}\right)+1 /\left(2-\delta_{i t+1}\right)^{2}+1 /\left[\left(1-\delta_{i t+1}\right)\left(2-\delta_{i t+1}\right)\right]<0
$$

As is clear from (11), parental aversion to changes in work norms across generations is necessary to ensure the concavity of parental utility function with respect to offspring's work norm. 
Totally differentiating (10) we first obtain $d \delta_{i t+l} / d \delta_{i t}>0$, implying intergenerational transmission of work norms. This result is well consistent with recent empirical work that testifies to the importance of the origin country in determining the earnings of second generation immigrants, see Borjas, 1993, 1995, and Fernandez and Fogli, 2007. The latter paper specifically focuses on culture as a crucial determinant of work attitudes, concluding that cultural factors are transmitted from the first to the second immigrant generations.

Further, differentiation with respect to income reveals that

$$
d \delta_{i t+1} / d y_{i t}=1 /\left[(\text { S.o.c })\left(y_{i t}+2 a_{t+1}\right)\right]<0
$$

so that the preferred work attitude for one's child is a decreasing (and convex as is revealed by differentiating the left-hand side in (12)) function of family income. The intuition for this result is as follows. To constrain the child's moral hazard, all parents consider strengthening work norms. Because of the income effect, the adverse implications of moral hazard for the parents are more detrimental in poorer families, where young work more, and who are then more willing to instill strict work norms in their children to induce a lower degree of shirking.

Summarizing,

Proposition 2. Parental work attitudes have a positive effect and parental incomes have a negative effect on instilled norms. 
We now examine the implication of these results for the next-period income. The latter can be written as follows:

$$
y_{i t+1}=\left(y_{i t}+a_{t+1} n_{i t+1}\right) / 2=\left(y_{i t}+2 a_{t+1}\right) / 2\left(2-\delta_{i t+1}\right)
$$

Differentiation of (13) reveals that $d y_{i t+1} / d \delta_{i t}=\left[\left(y_{i t}+2 a_{t+1}\right) / 2\left(2-\delta_{i t+1}\right)^{2}\right] d \delta_{i t+1} / d \delta_{i t}>0$, so that a stricter parental work attitude generates - through the instilling of stricter work norms in the children - a higher level of next-period income. Differentiation of (13) with respect to parental income yields:

$$
\begin{aligned}
& d y_{i t+1} / d y_{i t}=1 /\left[2\left(2-\delta_{i t+1}\right)\right]+\left[\left(y_{i t}+2 a_{t+1}\right) / 2\left(2-\delta_{i t+1}\right)^{2}\right] d \delta_{i t+1} / d y_{i t}= \\
& 1 /\left[2\left(2-\delta_{i t+1}\right)\right]+\left[1 / 2\left(2-\delta_{i t+1}\right)^{2}(\text { S.o.c })\right]
\end{aligned}
$$

In (14), the first term is positive - and decreases in income - to reflect the income effect that generates higher bequests, and the second term is negative because of the adverse income effect on work norms.

To further illustrate the transitional dynamics, consider two dynasties, with different (but similar) incomes and initially identical work attitudes, $y_{r 0}>y_{p 0}, \delta_{r 0}=\delta_{p 0}$. The above analysis implies that, in period 1, there will be divergence in work attitudes, the poor dynasty developing a stricter attitude than the rich dynasty, $\delta_{r l}<\delta_{p 1}$; correspondingly, income convergence will take place. To generate an example of the reversal of fortune, suppose that 
period 2's productivity is very large relatively to family incomes, $a_{2} \gg y_{r l}>y_{p 0}$. It then follows from (13) that period 1's differences in family incomes play a negligible role in determining period 2's incomes; in contrast, the differences in work attitudes is all that matters. ${ }^{15}$ These considerations lead to

Proposition 3. There is a possibility of an endogenous reversal in income ranking across some households from one period to the next.

This analysis helps identify the circumstances under which reversals of fortunes are more likely. When the next-period productivity is high, the differences in family incomes become less important relatively to the differences in work efforts by the young - which, in turn, hinge upon instilled work attitudes. This is when the stricter work attitude of the poor families translates into better fortunes for their descendants relative to the rich dynasties.

\section{Extensions}

We now discuss further extensions of the main framework.

\footnotetext{
${ }^{15}$ That this is not a knife edge scenario can be seen from the observation that if, initially, the rich family's work norm is stronger, $\delta_{r 0}>\delta_{p 0}$, the above analysis implies convergence in both work norms and, therefore, incomes.
} 


\section{Labor productivity and labor supply}

Labor productivity bears implications on differences in labor supply across individuals and their changes over time. Totally differentiating (7) with respect to income, we obtain:

$$
d n_{i t+1} / d y_{i t}=-\left(1-\delta_{i t+1}\right) /\left(2-\delta_{i t+1}\right)\left(1 / a_{t+1}\right)+\left(2+y_{i t} / a_{t+1}\right) /\left(2-\delta_{i t+1}\right)^{2}\left(d \delta_{i t+1} / d y_{i t}\right)<0
$$

so that labor supply is a decreasing function of family income. Note, however, that $d^{2} n_{i t+1} / d y_{i t} d a_{t+1}>0$, implying that the higher labor productivity the less steep is the decrease. This is consistent with Costa, 2000, who finds using the US data that the elasticity of labor supply with respect to income was steeply negative in the $1890 \mathrm{~s}$, but became much more moderate toward 1973.

Further, suppose now by way of extension that labor productivity, $a_{i t+l}$, consists of individual specific $\left(\varepsilon_{i t+1}\right)$ as well as of cohort specific $\left(a_{t+1}\right)$ components, $a_{i t+l}=a_{t+1} \varepsilon_{i t+l}$, where in each period $\varepsilon_{i t+l}$ is independently and identically distributed. The above analysis then goes through with $a_{i t+l}$ replacing $a_{t+l}$ everywhere. The equilibrium depends on labor productivity as well as on family income. It can then be shown through a direct extension of the above that $d \delta_{i t+1} / d \varepsilon_{i t+1}>0$, so that a higher individual labor productivity implies a stricter work norm. When the cohort specific component $a_{t+1}$ is small, implying a small relative weight of individual specific labor productivity, the differences in labor supply are mainly due to differences in parental income; but when it is large, the role of parental incomes is small relative to the role of labor productivity. In this case, variations in labor supply are primarily due to the variations in work attitudes, whereas the latter increase in labor productivity. This 
observation can be used to explain another finding in Costa, 2000, that the elasticity of labor supply with respect to income changed sign in the last decades of that past century: whereas until about 1973 it was negative, richer individuals working less, after that the relationship reversed itself. Specifically, this is consistent with an increase in the cohort specific component of labor productivity that reduced the relative importance of variation in family incomes and enhanced the importance of individual labor productivity differences.

\section{Income redistribution and work norms}

Consider next the effect of income redistribution policies. Redistribution is modeled by assuming that a proportional income tax, say $0 \leq T \leq 1$, is levied on period $t$ 's income to finance a lump sum next period transfer to every household. With such budget balanced redistribution scheme, the budget constraint each parent faces becomes:

$$
y_{i t}(1-T)=c_{i t}+b_{i t+1}
$$

whereas future household's income is given by:

$$
y_{i t+1}=T Y_{t}+a_{t+1} n_{i t+1}+b_{i t+1}
$$

where $Y_{t}$ is the average period $t$ income. The higher the tax rate the more intensive income redistribution. ${ }^{16}$ The sequence of events is as previously described.

Simple calculations reveal that the analysis of the last two stages of the period decision making is as above, with $z_{i t}=y_{i t}(1-\mathrm{T})+\mathrm{T} Y_{t}$ replacing $y_{i t}$ everywhere. ${ }^{17}$ We focus, therefore, on 
the third stage. The first order conditions determining the work attitudes are then as above, with $2-n_{i t+1}=\left(1-\delta_{i t+1}\right)\left(2+z_{i l} / a_{t+1}\right) /\left(2-\delta_{i t+1}\right)$,

$$
\left.\mathrm{C}^{\prime}\left(\delta_{i t+1}-\delta_{i t}\right)+1 /\left(2-\delta_{i t+1}\right)-\log \left[1-\delta_{i t+1}\right)\left(2+z_{i t} / a_{t+1}\right) /\left(2-\delta_{i t+1}\right)\right]=0
$$

Totally differentiating (16) and recalling the second order conditions, we obtain that the equilibrium work attitude increases in $T$ when $y_{i t}>Y_{t}$ and decreases in $T$ otherwise. Comparing high-redistribution with low-redistribution societies, this then implies that that work ethic is expected to be stricter among the rich and weaker among the poor in the former relative to the latter.

Totally differentiating with respect to $y_{i t}$ as in the above analysis yields

$$
d \delta_{i t+1} / d y_{i t}=(\text { S.o.c })\left(z_{i t}+2 a_{t+1}\right) /(1-\mathrm{T})<0
$$

and further differentiation reveals that $d^{2} \delta_{i t+1} / d y_{i t} d T<0$, implying that the inverse relationship between family income and work norms is steeper in redistributive societies.

\section{Richer channels of cultural transmission}

The relatively simple mechanism of cultural transmission studied in this paper could be extended by considering more general forms of social influences, oblique socialization in a

\footnotetext{
${ }^{16}$ A constant tax rate across time is assumed for simplicity.

${ }^{17}$ Thus, the amount of bequests as determined from the first order conditions in the last stage is $b_{i t+1}=\left(y_{i t}(1-\mathrm{T})\right.$ $\left.+\mathrm{T} Y_{t}-a_{t+1} n_{i t+1}\right) / 2$, so that $y_{i t+1}=\left(y_{i t}(1-\mathrm{T})+\mathrm{T} Y_{t}+a_{t+1} n_{i t+1}\right) / 2$; and $n_{i t+1}=\left[2-\left(1-\delta_{i t+1}\right)\left(y_{i t}(1-\mathrm{T})+\mathrm{T} Y_{t}\right)\right] /\left(2-\delta_{i t+1}\right)$ and 2- $n_{i t+1}=\left(1-\delta_{i t+1}\right)\left(2+\left(y_{i t}(1-\mathrm{T})+\mathrm{T} Y_{t}\right) / a_{t+1}\right) /\left(2-\delta_{i t+1}\right)$.
} 
broad context. Suppose, for instance, that a child's work norm, $\delta_{i t+1}{ }^{C}$, is shaped as, say, a weighted average of both own parental influence, $\delta_{i t+1}$, and of the average of all parents' influences, $\delta_{i t+l}^{C}=\alpha \delta_{i t+l}+(1-\alpha) \int_{0}^{1} \delta_{j t+1} d j, 0 \leq \alpha \leq 1$ (the case studied above corresponds to $\alpha$ $=1$ ). It can be shown then the larger values of $\alpha$ imply a lower elasticity of labor with respect to parental imposition of a work norm. This, in turn, implies a reduced willingness on the part of the parents to instill in their children a work norm that is different from their own as each parent attempts to "free ride" on other parents. As pointed out by a referee, this would weaken the commitment value of instilling strong work norms, thereby reducing the plausibility of income reversals. One possibility to reduce the free riding incentives in this context, briefly considered in a previous version of the paper, is by collective decision making on work norms, through, for example, the mechanism of public schooling. A detailed analysis of its ramifications is, however, beyond the scope of this paper.

\section{Concluding remarks}

This paper endogenizes the determination of work attitudes in a dynamic macroeconomic context. Its building block is intergenerational conflict of interests between parents and children that results in disincentives to generate adequate work effort in anticipation of parental transfer. Parental instilling of work norms is then an instrument to mitigate their moral hazard consequences, and the motive to use it decreases with income. Survey data indicate support for 
this inverse relationship. This, further, generates the possibility of dynastic reversals of fortune, whereby descendants of poor families overtake rich families' descendants.

The findings on convergence, in education and in earnings, between second generation immigrants and the natives, and even the overtaking of the latter by the former are consistent with the model's framework. Moreover, these pieces of evidence about reversals of fortunes pertaining to population groups also help to distinguish our model from the standard models of intertemporal mobility that rely on exogenous ability variations. Since ability is perceived in these models to be an individual specific characteristic, they do not seem to be generally consistent with the rise and fall of groups of individuals. In contrast, this paper's model generates predictions that may explain the emergence of group-specific norms relevant for these groups' economic success or failure.

Future research could proceed in at least two directions. One would be to try and relax some of the model's assumptions (exogenously given one offspring in each generation; limited altruism in regard to future generations that only pertains to one's immediate offspring; parental inability to indirectly commit bequests through indirect transfers, such as investing in education). Another, empirical avenue, would be a longitudinal analysis of labor decisions of second generation immigrants as compared to natives that could possibly lend further support to the paper's argument. 


\section{Appendix}

\section{Definitions of variables for Table 1}

\begin{tabular}{|c|c|}
\hline $\begin{array}{l}\text { "Work is what makes life worth living, } \\
\text { not leisure" }\end{array}$ & $\begin{array}{l}\text { The question: Which point on this scale most clearly describes how much } \\
\text { weight you place on work (including housework and schoolwork), as } \\
\text { compared with leisure or recreation? } \\
\text { (1) It's leisure that makes life worth living, not work, (2).., (3),..., } \\
\text { (4), (5) Work is what makes life worth living, not leisure. }\end{array}$ \\
\hline $\begin{array}{l}\text { "Work should always come first, even } \\
\text { if it mean less spare time" }\end{array}$ & $\begin{array}{l}\text { The question: Do you agree or disagree with the following statement? } \\
\text { Work should always come first, even if it means less spare time: } \\
\text { (1) Strongly disagree, (2) disagree, (3) neither agree or disagree, (4) } \\
\text { agree, and (5) strongly agree. } \\
\text { (Re-categorized in the opposite direction for consistency) }\end{array}$ \\
\hline Income scale & 1st lowest decile - 10th highest decile \\
\hline Women & Dummy: 1 Woman, 0 Man \\
\hline Education & $\begin{array}{l}\text { Years of education (incomplete primary: } 3 \text { / complete primary: } 6 \text { / } \\
\text { incomplete secondary: } 8.5 \text { / complete secondary: } 11 \text { / incomplete } \\
\text { secondary university prep.: } 12.5 \text { / complete secondary university prep: } 14 \\
\text { / inocmplete university: } 13.5 \text { / complete university }\end{array}$ \\
\hline Marital status & Dummies: Married / Separate, divorced or widow / Single (Omitted) \\
\hline
\end{tabular}




\section{References}

Becker, G., 1974, “A Theory of Social Interactions,” Journal of Political Economy, 82, 1063 1093.

Becker, G., 1981, A Treatise on the Family, Harvard University Press, Cambridge, MA.

Becker, G. and N. Tomes, 1988, "Human capital and the rise and fall of families," Journal of Labor Economics, S1-S39.

Becker, S. and L. Woessmann, 2007, "Was Weber wrong? A human capital theory of Protestant economic history," mimeo.

Bernheim, D. and S Severinov, 2003, "Bequests as Signals: An Explanation for the Equal Division Puzzle," Journal of Political Economy 111, 733-764.

Bertocchi, G., 2006, "The law of primogeniture and the transition from landed aristocracy to industrial democracy," Journal of Economic Growth, 11, 41-68.

Bisin, A. and T. Verdier, 2001, "The economics of cultural transmission and the dynamics of preferences," Journal of Economic Theory, 97, 298-319.

Borjas, G.J., 1993, "The intergenerational mobility of immigrants," Journal of Labor Economics, 11, 113-134.

Borjas, G.J., 1995, "Assimilation and changes in cohort quality revisited: What happened to immigrant earnings in the 1980s?" Journal of Labor Economics, 13, 201-245.

Botticini, M. and Z. Eckstein, 2005, "Jewish occupational selection: Education, restrictions, or minorities?" Journal of Economic History, 65, 922-948.

Botticini, M. and Z. Eckstein, 2006, "From farmers to merchants, voluntary conversion and diaspora: A human capital interpretation of Jewish history," Journal of the European Economic Association, forthcoming.

Boyd R. and P.J. Richerson, 1985, Culture and the Evolutionary Process, University of Chicago Press.

Card, D., 2005, "Is the new immigration really so bad?" Economic Journal, F300-F323. 
Carliner, G., 1980, "Wages, earnings, and hours of first, second, and third generation American males," Economic Inquiry, 87-108.

Cavalli-Sforza, L.L. and M. W. Feldman, 1981, Cultural Transmission and Evolution: A Quantitative Approach, Princeton University Press, Princeton, NJ.

Chiswick, B.R., 1977, "Sons of immigrants: Are they at an earnings disadvantage?" American Economic Review P\&P, 376-380.

Chiswick, B.R., 1978, "The effects of Americanization on the earnings of foreign-born men," Journal of Political Economy, 86, 897-921.

Costa, D.L., 2000, "The Wage and the Length of the Work Day: From the 1890s to 1991," Journal of Labor Economics, 18, 156-181.

Doepke, M. and F. Zilibotti, 2005, "Social class and the spirit of capitalism," Journal of the European Economic Association, 3, 516-524.

Doepke, M. and F. Zilibotti, 2007, "Occupational choice and the spirit of capitalism," mimeo.

Eccles, J.S., Wigfield, A., and U. Sciefele, 2000, "Motivation to succeed," in Handbook of Child Psychology, vol. 3, Social, Emotional, and Personality Development, 5th Edition

Damon, W. (Editor-in-Chief), Eisenberg, N. (Editor), Wiley, New York.

Fernandez, R. and A. Fogli, 2007, "Culture: An empirical investigation of beliefs, work, and fertility," mimeo.

Galor, O. and O. Moav, 2002, "Natural selection and the origin of economic growth," Quarterly Journal of Economics, 117, 1133-1191.

Galor, O. and O. Moav, 2006, "Das Human Kapital: A theory of the demise of the class structure," Review of Economic Studies, 73, 85-117.

Galor O. and D. Tsiddon, 1997, "Technological progress, mobility, and economic growth," American Economic Review, 87, 363-382.

Gatti, R., 2005, "Family altruism and incentives," Scandinavian Journal of Economics, 107, 67-81.

Gradstein, M. and M. Justman, 2002, "Education, Social Cohesion, and Economic Growth," American Economic Review, 92, 1192-1204. 
Hammarstedt, M. and M. Palme, 2006, "Intergenerational mobility, human capital transmission and the earnings of second-generation immigrants to Sweden," IZA WP 1943.

Jacob, B.A. and L. Lefgren, 2007, "What do parents value in education? An empirical investigation of parents' revealed preferences for teachers," NBER WP 11494, Quarterly Journal of Economics, forthcoming.

Lindbeck, A. and S. Nyberg, 2006, "Raising children to work hard: Altruism, work norms, and social insurance," Quarterly Journal of Economics, 121, 1473-1503.

Loury, G., 1981, "Intergenerational transfers and the distribution of earnings," Econometrica, 49, 843-867.

Maoz, Y. and O. Moav, 1999, "Intergenerational mobility and the process of development," Economic Journal, 109, 677-697.

Mookherjee, D. and S. Napel, 2006, "Intergenerational Mobility and Macroeconomic History Dependence," Journal of Economic Theory, forthcoming.

Sowell, T., 1996, Migration and Cultures. A World View, Basic Books, New York.

World Values Surveys, http://www.worldvaluessurvey.org/ 
Table 1: Regression analysis of work attitudes

\begin{tabular}{|c|c|c|c|c|}
\hline & \multicolumn{2}{|c|}{$\begin{array}{l}\text { "Work is what makes life wortl } \\
\text { living not leisure" }\end{array}$} & \multicolumn{2}{|c|}{$\begin{array}{l}\text { "Work should always come } \\
\text { first, even if it means less } \\
\text { spare time" }\end{array}$} \\
\hline & (1) & $(2)$ & (3) & (4) \\
\hline Income & $\begin{array}{l}-0.030 * * * \\
(0.008)\end{array}$ & $\begin{array}{c}-0.021 * * * \\
(0.007)\end{array}$ & $\begin{array}{l}-0.052 * * * \\
(0.005)\end{array}$ & $\begin{array}{l}-0.035 * * * \\
(0.004)\end{array}$ \\
\hline Education & & $\begin{array}{l}-0.013 * * * \\
(0.004)\end{array}$ & & $\begin{array}{l}-0.030 * * * \\
(0.004)\end{array}$ \\
\hline Gender: female & $\begin{array}{c}0.002 \\
(0.017)\end{array}$ & $\begin{array}{l}-0.006 \\
(0.017)\end{array}$ & $\begin{array}{c}-0.119 * * * \\
(0.014)\end{array}$ & $\begin{array}{l}-0.126 * * * \\
(0.014)\end{array}$ \\
\hline Marital status: married & $\begin{array}{l}0.159 * * * \\
(0.033)\end{array}$ & $\begin{array}{c}0.132 * * * \\
(0.027)\end{array}$ & $\begin{array}{l}0.276^{* * * *} \\
(0.028)\end{array}$ & $\begin{array}{l}0.235 * * * \\
(0.027)\end{array}$ \\
\hline $\begin{array}{l}\text { Marital status: } \\
\text { divorced, separated or } \\
\text { widow }\end{array}$ & $\begin{array}{c}0.166 * * * \\
(0.044)\end{array}$ & $\begin{array}{c}0.135^{* * *} * \\
(0.041)\end{array}$ & $\begin{array}{c}0.333 * * * \\
(0.036)\end{array}$ & $\begin{array}{c}0.284 * * * \\
(0.034)\end{array}$ \\
\hline Observations & 47327 & 46914 & 64982 & 64677 \\
\hline Pseudo R-Squared & 0.08 & 0.08 & 0.07 & 0.07 \\
\hline
\end{tabular}

Robust standard errors are in parentheses. All regressions include country dummies and standard errors adjusted for country level clustering

* Significant at ten percent; ** significant at five percent; *** significant at one percent. 